\title{
Gerold Heinrichs, Apollonia Pane Where are the results? Open access for research coordination projects financed by the EU
}

\begin{abstract}
Open access to the results of publicly funded research is one of the European Commission's avowed goals. Yet how far is open access actually realised in practice? This article explores the issue based on a subsection of the projects financed by the EU: research coordination projects. The results of these projects rarely appear in international journals that implement peer review processes; instead, they are mainly published as grey literature and therefore pose a special challenge in terms of open access. Following explanation of the theoretical conditions for open access applying to EU-funded research projects, 26 international research coordination projects with Asian participation that constitute part of the 7th Framework Programme for Research (FP7) are analysed. The difficulties encountered when implementing open access for these projects are outlined. Finally, the authors describe a possible solution which could guarantee straightforward access to the results of research coordination projects in the long run.
\end{abstract}

Freier Zugang zu den Ergebnissen von öffentlich finanzierter Forschung ist erklärtes Ziel der Europäischen Kommission. Doch inwieweit wird Open Access in die Praxis umgesetzt? Dieser Artikel geht der Frage am Beispiel eines Teilbereichs EU-finanzierter Projekte nach: Projekte der Forschungskoordination. Ergebnisse solcher Projekte werden selten in internationalen Zeitschriften mit peer-review Verfahren veröffentlicht, sondern hauptsächlich als Graue Literatur, und stellen daher mit Blick auf Open Access eine besondere Herausforderung dar. Nach einer Erläuterung der theoretischen Rahmenbedingungen für Open Access innerhalb EU-finanzierter Forschungsprojekte, werden 26 Vorhaben der internationalen Forschungskoordination mit asiatischer Beteiligung innerhalb des 7. Forschungsrahmenprogramms (FP7) analysiert und anhand dieser die Schwierigkeiten bei der Umsetzung von Open Access skizziert. Anschließend zeigen die Autoren einen möglichen Lösungsweg auf, um einen langfristigen und unkomplizierten Zugang zu Ergebnissen aus Projekten der Forschungskoordination zu sichern.

\section{Introduction}

Open access, i. e. free (usually digital) access to the results of publicly funded research, is playing an increasingly important part in the dissemination of scientific information. Access to information classified as 'public' should be made as straightforward as possible. From a research policy perspective, scientists, businesses and the general public should benefit most from this. Numerous research sponsors, individual EU states and also the European Commission - as the most important funding body for research and innovation in Europe - want to be sure that the results acquired with the help of tax revenues can be deployed by as many people as possible. If they are processed by other users, they can help make research more efficient and accelerate innovations. The researchers themselves and their employers (no matter whether they are private companies or public research institutions) are in turn keen to be able to rely on their colleagues' findings when doing their own work. Even though the concept of comprehensive open access is criticised in terms of author rights and quality assurance, ${ }^{1}$ there is a general consensus that the results of publicly funded research projects should be freely accessible in order to increase the quality and efficiency of science. Moreover, the general increase in the transparency of science guaranteed by open access leads to stronger social participation, thus increasing the level of acceptance for research (and its funding). ${ }^{2}$

This fundamental consensus on the topic of open access is also reflected by the EU Commission's flagship initiatives: Open science including open access ${ }^{3}$ are described as the basis of successful innovation and consequently of growth in the European Union by the Digital Agenda for Europe, the Innovation Union Policy and in the implementation of the European Research Area (ERA). ${ }^{4}$ The principles formulated as part of these initiatives 
form the foundation of the document on the EU Commission's open access policy that was presented in $2012 .{ }^{5}$ Since the publication of these documents, open access can be viewed as one of the Commission's core strategies for strengthening the European innovation system.

Based on these facts, this article deals with the question of how current open access requirements are practically met in certain rather atypical instances. How does open access to the findings of EU-funded projects of research coordination, i. e. not pure research projects, function in practice? Using a subsection of the projects under the EU Commission's 7th Framework Programme for Research (FP7) as the basis, this investigation aims to analyse the accessibility of the public results of EU-funded international research coordination projects. Unlike the results of FP7 research projects, the results of research coordination projects are rarely published in international journals with peer review procedures; instead, they are mainly published as grey literature ${ }^{6}$. Research coordination projects are horizontal measures that deal with general issues relating to innovation systems, research collaboration, research funding and similar matters. Projects of this type frequently contain analytical work packages. In many cases, the papers that ensue become the basis of policy consulting. In addition these projects also often focus on analysis and methodical approaches to research funding and evaluation. As described below, this type of work and the resulting publications pose a special challenge in terms of open access that cannot be compared with other research projects producing other types of publications (particularly peer-reviewed thematic articles in scientific journals).

As a first step, we will explore the theoretical framework conditions for open access applying to the results of EU-funded research projects. Afterwards, we will outline the challenges and difficulties connected to the EU's existing open access requirements by analysing 26 FP7 international research coordination projects with Asian participation. Various possible paths are examined and finally a solution is presented.

\section{Open access requirements within the European Commission}

While the importance of open access for a successful innovation system was already becoming evident at the time of FP7 (2007-2013, drafting of the above-mentioned documents in 2012), further important steps towards implementation were taken under Horizon2020 (2014-2020). The Horizon guidelines define open access as "the practice of providing online access to scientific information that is free of charge to the end-user and that is re-usable." It further states that "scientific information" refers to "(i) peerreviewed scientific research articles (published in scholarly journals) or (ii) research data (data underlying publications, curated data and/or raw data)."7

Based on this classification, Horizon comprises two different measures that are to promote the implementation of open access: firstly, all projects which receive EU funds under Horizon are expressly obliged to make all peer-reviewed publications produced during the projects, accessible free of charge through "green open access" or "gold open access". ${ }^{8}$ Secondly, Horizon contains a pilot programme in which participating projects must also enable open access to the basic research data. As so far there is only little experience with this, open access to research data is not yet obligatory for all Horizon projects. ${ }^{9}$

The obligation of peer-reviewed publications to grant open access is justified in the guidelines for Horizon as follows: "The European Commission's vision is that information already paid for by the public purse should not be paid for again each time it is accessed or used, and that it should benefit European companies and citizens to the full. This means making publicly-funded scientific information available online, at no extra cost, to 
European researchers, innovative industries and citizens, while ensuring long-term preservation." 10

The framework documents and handouts for FP7, Horizon's predecessor, include initial attempts to implement open access, although less clearly formulated than under Horizon. Grant agreements concluded under FP7 merely oblige the beneficiary to make the results of his research classified as 'public', actually available to the public; however, no details are given as to how this should be put into practice in individual cases. ${ }^{11} \mathrm{FP7}$ also encompassed an open access pilot programme: the projects involved, commit themselves to guaranteeing open access to scientific articles written in connection with their projects. The aim was to publish final articles (which should, if possible, have undergone a peer review process) either through a repository maintained by the institutions involved or - if this was not possible - through a suitable thematic repository. The document on the open access pilot programme in addition states: "The European Commission encourages all grant recipients (not only those covered by the open access pilot) to consider the question of open access when submitting their articles for publication. This not only provides greater visibility to their work, thereby potentially leading to more citations and greater research impact, but also reduces the likelihood of wasting time and public resources on duplicative research." 12

In order to promote this approach, a FP7 project with the name 'OpenAIRE' was set up. OpenAIRE aims at creating a digital infrastructure which should facilitate identification, archiving, control and access to articles funded by the EU Commission. ${ }^{13}$ The post-grant open access pilot published in October 2015 represents another step in this direction. This pilot will subsidise open access publications compiled in connection with completed FP7 projects by covering the costs of publication. ${ }^{14}$ The Commission seems to have realised that more support is needed in this context.

\section{Open access to results of FP7 I NCO projects with Asian participation}

\section{Projects investigated}

The projects investigated in this article belong to the INCO programme, which itself is a building block for the Capacities component of 7th Framework Programme for Research. All the INCO projects are horizontal measures for the promotion of international cooperation in the field of research coordination. The INCO projects encompass a total funding volume of EUR 180 million. ${ }^{15}$ In the following investigation, all 26 INCO projects with Asian participation (excluding projects solely with central Asian participation) are examined in detail. As of the time this article was being researched (April 2015), 15 of the projects had been concluded and 11 were still running. The total funding for this group of projects amounted to more than EUR 41 million. ${ }^{16}$

With regard to the projects chosen for this article, special reference should again be made to the peculiarity mentioned above: As the projects are horizontal measures, the project results - unlike more thematically oriented programme components - rarely include any publications that take the form of scientific articles in peer-reviewed journals. This means the results do not usually come under the FP7 or Horizon definition of articles for which open access is recommended - or even obligatory under Horizon. Nevertheless, the results obtained and documented during these projects were financed with public funds and should therefore be freely accessible: All the above-mentioned advantages of granting open access to peer-reviewed scientific articles, i. e. increased quality, efficiency and public acceptance, also apply to these project results. In the case of the projects investigated, the publications usually comprise information papers, data collections, evaluations or (political) recommendations compiled in English that could be beneficial for cooperative projects in the respective areas both at the level of research management and for the actual research. ${ }^{17}$ Even though the Commission, neither under FP7 nor under 
Horzion2020, has stipulated the granting of open access to these kinds of documents, it seems only consistent to do so.

\section{Investigation and results}

Which possibilities currently exist for retrieving the results of FP7 INCO projects with Asian participation which are classified as public and only available as grey literature, e. g. project reports, brochures, methodical approaches, handbooks, best practice collections and conference reports? At first glance, three obvious ways can be identified:

a) direct access through publication by the projects themselves (normally using project websites);

b) direct access through an EU Commission platform on which all results are made available in a structured format (Cordis);

c) indirect search via general internet search engines.

As the following investigation shows, all three ways are of limited suitability at best for finding the documents required. However, while carrying out the research for this article, another way was identified which, in the long term, would guarantee structured access to the results with little outlay.

\section{a) Access through publication on (project) websites by the projects themselves or the institutions involved}

The regulations for publishing results specified by FP7 and Horizon allow the project coordinators a certain scope when choosing the place of publication. As one frequently used method is to make the information available on a website set up by the project, we started by investigating the availability of project results on corresponding websites. For this, we searched for the websites of the projects concerned or - if no such website could be found - for alternative websites with access to the project results (e. g. the websites of the institutions involved). The internet URL usually includes the project acronym which can easily be found on the websites of the EU programmes. 20 of the 26 projects investigated had their own project websites. Four projects published information on other websites. For the remaining two projects no relevant website could be found (see Fig. $1(\mathrm{a}))$.

The next step was to examine the content available on the websites found - usually the results defined in the project plan, otherwise known as 'deliverables'. The first question was whether the work packages for the respective project actually contained any deliverables that could be depicted appropriately on a website. ${ }^{18}$ The majority of the deliverables for 23 of the projects can be meaningfully published on websites; only three projects have varying goals that at best can only be partly published on the internet. These three projects are therefore not considered in the following evaluation. Three more projects were also excluded from the following evaluation because their websites are identical to those of the respective follow-up projects. Projects and follow-up projects that share a website are only considered once when investigating the deliverables available.

Of the 20 projects that we examined more closely, no deliverables whatsoever were found for three projects. For the other 17 projects, results could in principle be retrieved via the websites found (see Fig. 1(b)). The three projects for which no deliverables were available included the two projects for which no website could be found and another project for which only an alternative website was found. 

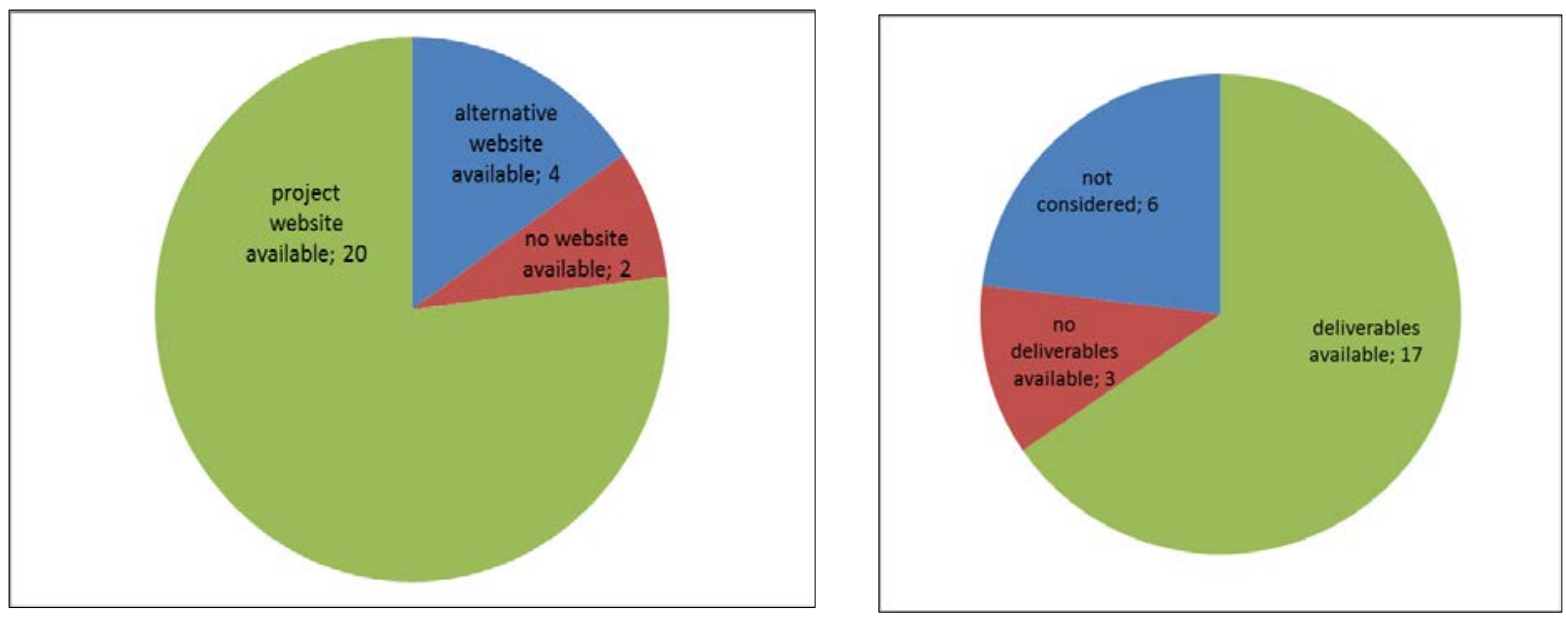

Fig. 1: (a) Existing relevant (project) websites and (b) fundamental availability of deliverables via these websites (source: own investigation, see annex separately uploaded online; address at the end of the article)

The next step was comprised of the investigation and evaluation of the publicly accessible content found. Even though the individual texts could not be read in their entirety and there was no specific quality standard, a review of the texts still allowed a classification in three categories: 1) clearly comprehensible, structured, transparent content, 2) content of varying quality and 3) missing content or content that could only be understood with difficulty. Particular attention was paid to quantity (number of deliverables compared to the results originally mentioned in the project description) and quality (scope of the individual texts, topicality, language used, formal depiction). The deliverables for seven of the projects analysed made a very good impression, while the impression was mixed for the deliverables of another ten projects. In the latter cases, some of the results mentioned in the work packages could not be found at all, were only available in Asian languages, had no formal structure and/or were difficult to understand.

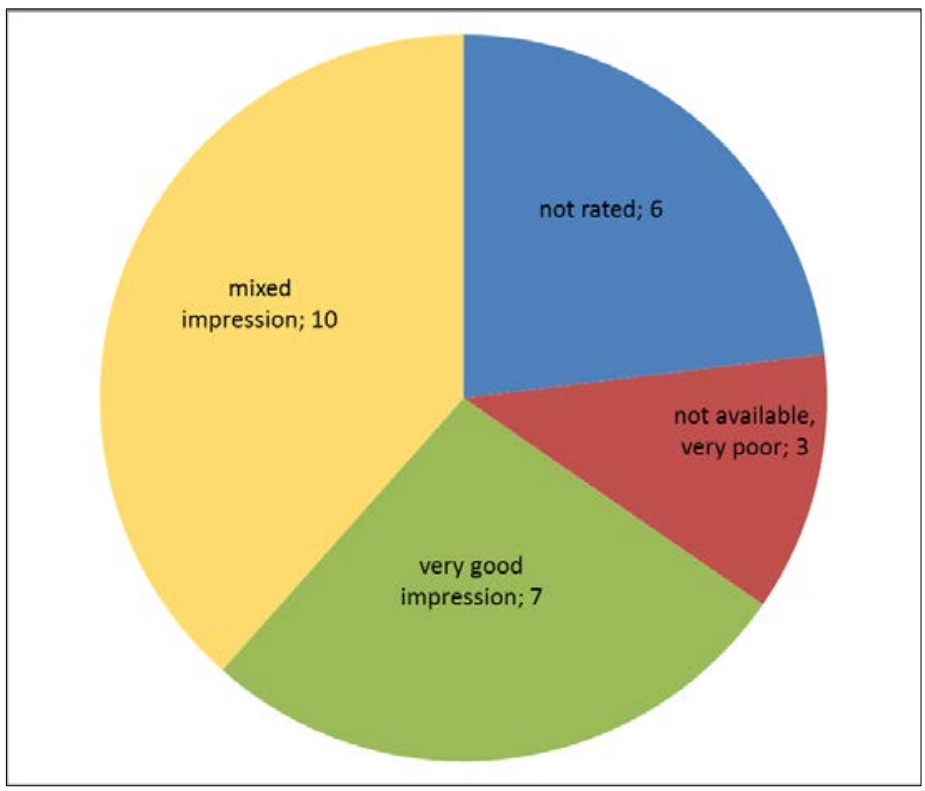

Fig. 2: Evaluation of the results available (source: own investigation, see annex) 
From the research results described above, it is clear that access to the results of the projects investigated by means of a specific project website is only possible to a limited extent. The result is satisfactory in less than a quarter of cases. There turned out to be three fundamental problems: Firstly, a comparison of the work package descriptions and the deliverables actually found, led us to the conclusion that the project results published on the websites are often incomplete. This means that the project partners themselves do not make extensive use of this publication channel. Secondly, access is difficult for interested searchers. The limited duration of the projects and the websites' preprogrammed expiration dates both play a role in this context: With regard to the projects whose results could not be found through this investigation (there was no (longer a) website) two had already expired before February 2012. Finally, the general complexity of this type of access is a fundamental problem: Anyone who is not familiar with the project (and consequently also with the website and actual titles of possible publications) has hardly any chance of finding the corresponding results by performing a keyword search if they were only published on the project website. Even if the project is generally known, our research shows that it is not always easy to find the corresponding website and then to find the published texts on this website. ${ }^{19}$

To conclude, the first alternative investigated proved to be unsuitable for long-term access and for backing up results on the long run. This option yielded no results at all for three of the projects, which had received a total amount of funding of more than EUR 3 million. In the case of the deliverables from projects with a total funding volume of more than EUR 11 million, this method only allows incomplete access to the results and this also only after some considerable effort.

\section{b) Access via EU Commission platforms}

The main eligible EU Commission platform identified is the Cordis database. Cordis allows targeted research regarding the basic data of the projects funded (partners, budget, goals etc.) and in most cases also grants access to the final report. According to its website, Cordis is "the European Commission's primary public repository and portal to disseminate information on all EU-funded research projects and their results in the broadest sense" ${ }^{20}$ - it is therefore an obvious place to search for project results. However, for the projects investigated, just one reference to a publication compiled as part of one of the projects was found: For the NEW INDIGO project, below the links to various report documents available for download on Cordis there is a link to an article compiled as part of the project and published in an open access journal. Cordis marks this link with an open access symbol and a reference to the OpenAIRE project mentioned above. ${ }^{21}$ OpenAIRE itself does not offer any direct repository options for publications; instead, it acts as a hub for information about projects and their results. This means that project results in the form of articles, reports etc. that were uploaded to open access journals (gold access) or appropriate open access repositories (green access) can be matched with the respective funding programme and consequently the project through OpenAIRE. This allotment by OpenAIRE in turn creates a link on the Cordis website that links to the respective open access publication.

In theory, central Commission platforms can be used to access the results of the projects investigated, i. e. via Cordis and the OpenAIRE website. In reality, however, this option is not used by the projects analysed here except for the case mentioned. ${ }^{22}$ The content of the projects investigated is therefore not made publicly available via the Commission websites. There is accordingly no improvement of the poor availability of information on the projects as described under a). 


\section{c) Indirect search using general internet search engines}

Nowadays, the most common method is to search for content on the internet by using search engines. Depending on the search term, these list results that are normally ordered by visit frequency. If this method is chosen, the most common word combinations (e. g. "research cooperation India") mostly lead to the project websites with the limitations described above - that is, if the projects are still under way. Completed projects whose websites are no longer visited frequently are only found a long way down in the list of results. The fundamental problem of websites that cease their activity when the project ends, is also relevant here. Our investigation showed that this open search form did not yield any additional content or results (e. g. on the websites of participating partners) for the projects analysed.

Currently the best way: publication in open access journals or repositories and additional link to Commission platforms

The basic requirement for access to the results through Cordis (or OpenAIRE) is that the corresponding texts have been uploaded in a structured manner to open access journals or corresponding open access repositories and did not end up - frequently with no structure or quality requirements - on project websites with an expiry date. Numerous such journals and repositories have been established since the open access movement got under way more than a decade ago. For the projects analysed here, the themes and formats of the project results frequently preclude publication in an open access journal (i. e. by gold open access). In contrast, green access publication with the aid of repositories is both possible and logical.

Repositories can be either open or theme-based. The OpenAIRE-website includes a list of so called "compliant repositories" which can be used to upload relevant results of EUprojects and thereby not only guarantee open access to these data but also establish a linkage to the corresponding EU-funded projects. Many of the repositories listed on OpenAIRE are institutional or subject-specific repositories that do not usually come into question for grey literature, such as the literature analysed in our context. From those open repositories which are suitable for the kind of literature investigated here, we identified Zenodo as a repository which fitted our needs: Zenodo is an open access repository created as part of the OpenAIRE project ${ }^{23}$ that is primarily intended for storing articles compiled during FP7 or Horizon 2020 projects which cannot be published meaningfully through an institutional or thematic repository. ${ }^{24}$ This means that Zenodo meets all the criteria for the archiving of results from the INCO projects analysed here with the aim of guaranteeing long-term accessibility. ${ }^{25}$ Moreover, OpenAIRE classifies Zenodo as compliant, i. e. information on possible project origin of the documents is requested when collecting the data for the document to be uploaded (grant agreement number of the project). If the grant agreement number is quoted when uploading a publication to Zenodo, OpenAIRE creates a link to the corresponding EU project that is then mirrored in Cordis in the form described above. ${ }^{26}$ The following diagram (Fig. 3) shows the considerations so far and also the solution described. 


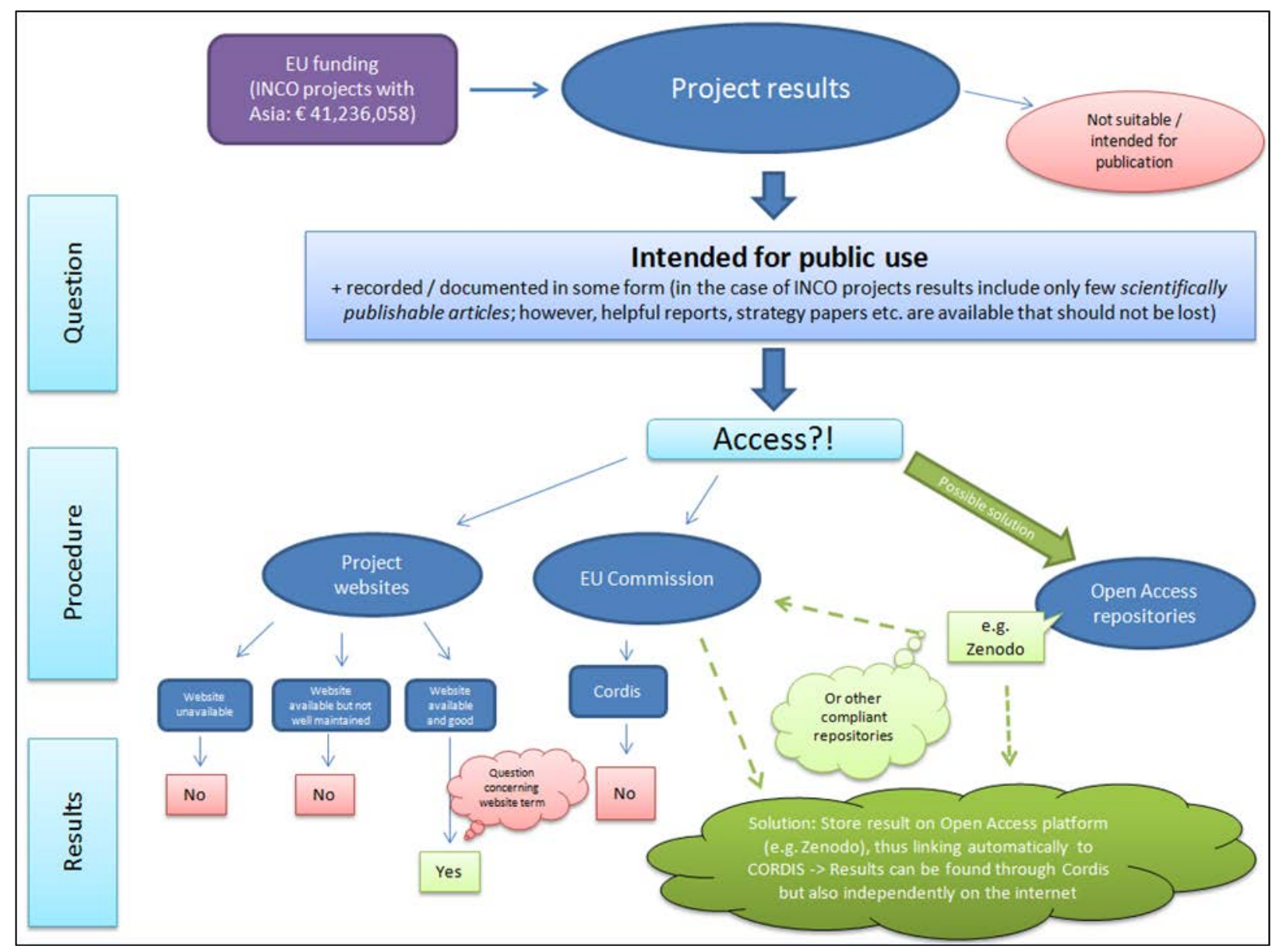

Fig. 3: Outline of investigation and results (source: own illustration)

The fact that the results of the projects researched here have not yet been stored on Zenodo (or any other suitable and ideally compliant repository) - and can therefore not be retrieved through OpenAIRE or Cordis - can in part be explained by insufficient awareness of this possibility. Without a doubt, another reason for this is that the Commission did and does not make it obligatory to grant open access to FP7 and Horizon2020 project results that are not based on scientific articles in peer-reviewed journals. If project participants do make their results available through repositories such as Zenodo, this is largely intrinsically motivated. The lack of external pressure to guarantee long-term open access to grey literature of this type is reinforced by a lack of information on the topic. On the basis of their own experience, the authors assume that many parties involved in the projects investigated here are not aware of Zenodo and its possibilities. The authors themselves had no knowledge of the existence of Zenodo or the link between Zenodo, OpenAIRE and Cordis when they commenced their investigations.

\section{Conclusion}

With a view to the EU Commission's long-term objective of open access and open science, the investigations outlined above show that although simple solutions exist for achieving this target on a larger scale, there is still a need for action.

A major step forward has been taken by compelling Horizon projects to guarantee open access to peer-reviewed publications (and in part to research data). The technical conditions for a relatively structured archive are also met using the system described 
above with the corresponding links through Cordis, OpenAIRE and a repository or open access journal of choice. This method of publication entails little extra expense for the project participants and is also attractive, as storage in a repository means that a larger target group is addressed and informed of the results of their work. From the viewpoint of interested searchers, storage in an open access medium allows the easiest way of accessing project results as key words can be searched for without needing to know the name of the project, the project website or the title of the publication.

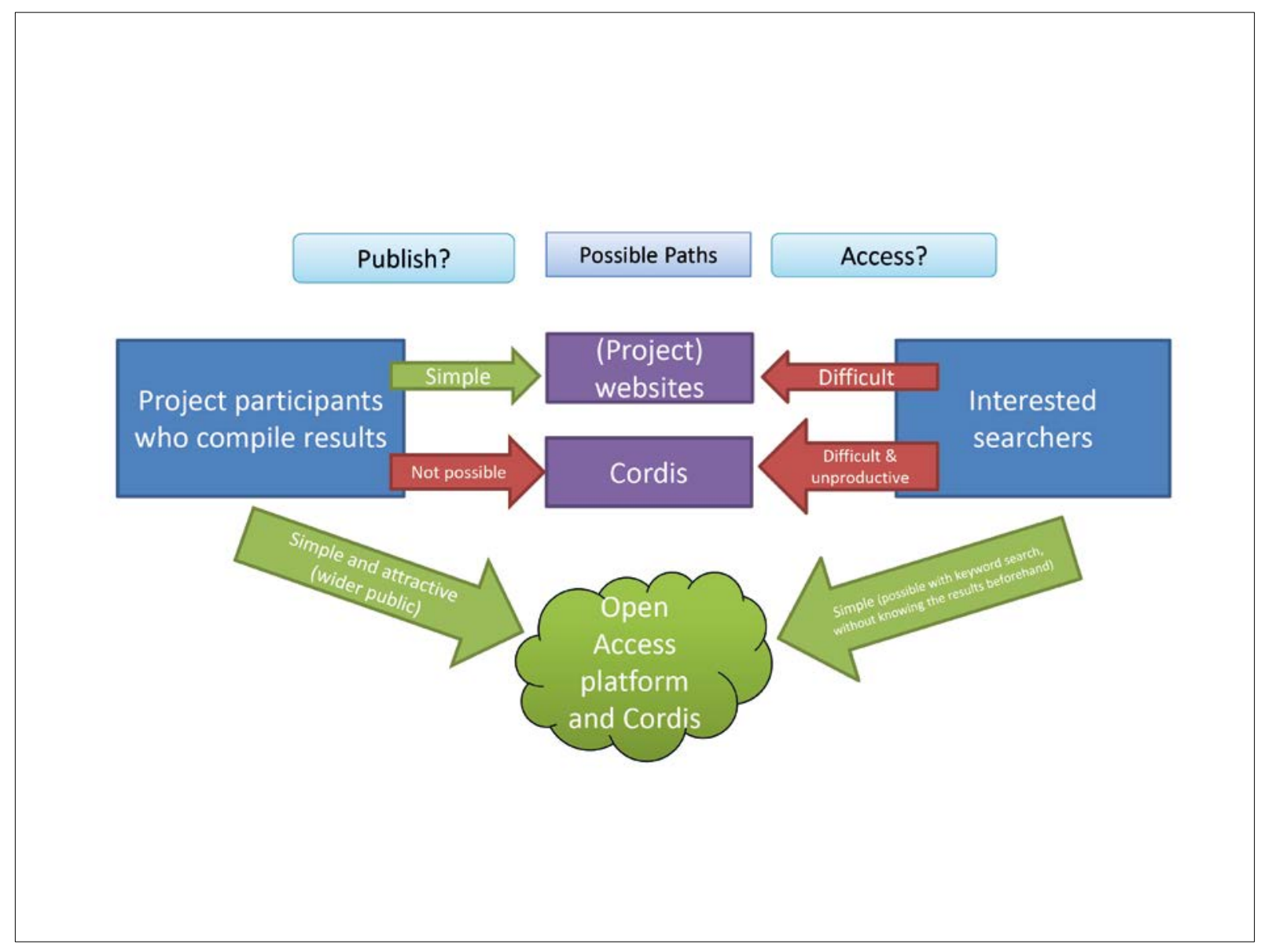

Fig. 4 Various open access routes to EU project results from two perspectives: Alternatives to the publication of and search for results by interested external parties (source: own illustration)

This publication method also guarantees straightforward, long-term access to content and results funded by FP7 and Horizon2020 that do not constitute research results per se but which are nevertheless practically relevant in the context of research management and coordination. The benefits obtained by these types of project results do not end when the project is completed or the project website is no longer available online. The long-term availability of results therefore appears highly desirable. In order to guarantee long-term open access, projects must be strongly recommended or compelled to prepare their results accordingly and store them appropriately, and project participants must be given more information about the publication options available. 


\section{ANNEX}

The annex to this article including a detailed list of the projects researched and a comprehensive process description for the possible solution found, can be downloaded from the internet using the following URL: http://internationales-

buero.de/media/content/OpenAccess_Annex.pdf

\section{SOURCES}

\section{Papers, Documents and Guidelines}

European Commission (2012): Communication from the Commission to the European Parliament, the Council, the European Economic and Social Committee and the Committee of the Regions - Towards better access to scientific information: Boosting the benefits of public investments in research. Available here: http://eur-

lex.europa.eu/LexUriServ/LexUriServ.do?uri=COM: 2012:0401: FIN: EN: PDF [ last access 02.01.2016].

European Commission (2012b): Commission Recommendation of 17 July 2012 on access to and preservation of scientific information. Available here:

http://ec.europa.eu/research/science-

society/document_library/pdf_06/recommendation-access-and-preservation-scientificinformation_en.pdf [last access 02.01.2016].

European Commission (2012c): FP 7 Grant Agreement - Annex II General Conditions, Version 7, 14/12/2012, especially „Part C, II.30. Intellectual property rights, use and dissemination - Dissemination". Available here:

http://ec.europa.eu/research/participants/data/ref/fp7/93289/fp7-ga-annex2_en.pdf [last access 02.01.2016].

European Commission (2013): HORIZON 2020 - Guidelines on Open Access to Scientific Publications and Research Data in Horizon 2020. Available here:

http://ec.europa.eu/research/participants/data/ref/h2020/grants_manual/hi/oa_pilot/h2 020-hi-oa-pilot-guide_en.pdf [ last access 02.01.2016].

European Commission ( 2015): Annotated Model Grant Agreement: H2020 General MGA: V2.0.1 - 12.05.2015, especially article 29 on dissemination of results. Available here:

http: //ec.europa.eu/research/participants/data/ref/h2020/grants_manual/amga/h2020amga_en.pdf\#page=209 [last access 02.01.2016].

European Commission (publication date unknown): Open Access Pilot in FP7. Available here: ftp://ftp.cordis.europa.eu/pub/fp7/docs/open-access-pilot_en.pdf [last access 02.01.2016].

OECD Working Party on I nnovation and Technology Policy (2014): Making Open Science a Reality - Final Report.

\section{Other Sources}

European Commission: CORDIS Community Research and Development I nformation Service, FP7-I NCO FP7 Specific Programme 'Capacities' Horizontal actions and measures in support of international cooperation. Available here: http://cordis. europa.eu/programme/rcn/865_en.html [last access 02.01.2016]. 
European Commission: CORDI S Community Research and Development I nformation Service, About Cordis. Available here:

http://cordis. europa.eu/guidance/home_en.html [last access 02.01.2016].

European Commission: CORDI S Community Research and Development I nformation Service, OpenAI RE entry. Available here:

http://cordis. europa.eu/project/rcn/93855_en.html [last access 02.01.2016].

European Commission: CORDIS Community Research and Development I nformation Service, NEW I NDI GO entry. Available here:

http://cordis. europa.eu/project/rcn/90360_en.html [last access 02.01.2016].

European Commission: Research \& Innovation, Open Science (Open Access) Policy; website (including chronology on Open Access in the European Commission): http://ec.europa.eu/research/swafs/index. cfm?pg=policy\&lib=science [ last access 02.01.2016].

European Commission: Digital Agenda for Europe: Open Access to scientific information. Available here: http://ec.europa.eu/digital-agenda/en/open-accessscientific-knowledge- 0 [last access 02.01.2016].

European Commission: European Research Area: Optimal circulation, access to and transfer of scientific knowledge. Available here:

http://ec.europa.eu/research/era/optimal-circulation_en.htm [last access 02.012016].

European Commission Library and e-Resources Centre: Open Access to

Research. Available here: http://www. netvibes.com/open-access\#Home [last access 02.01.2016].

Glossar I nformationskompetenz (Vermittlung von Informationskompetenz an deutschen Bibliotheken): Definition Graue Literatur. Available here (only available in German): www.informationskompetenz.de/glossar/?term $=418$ [last access 02.01.2016].

OpenAI RE website: FP7 post-grant Open Access publishing funds pilot. Available here: https://www.openaire.eu/postgrantoapilot [last access 02.01.2016].

OpenAI RE Website: General I nformation. Available here:

https: //www.openaire.eu/about/general-information/openairefactsheet-40 [last access 02.01.2016].

Suber, Peter: Open Access Overview. Available here:

http://legacy.earlham.edu/ peters/fos/overview.htm [last access 02.01.2016].

Zenodo: FAQs Website. Available here: www.zenodo.org/faq [last access 02.01.2016].

\section{The Authors}

Dr. Gerold Heinrichs, Head of Division "European and International Cooperation America, Asia and Oceania,", Deutsches Zentrum für Luft- und Raumfahrt e. V. (DLR), Heinrich-Konen-Straße 1, 53227 Bonn, Tel.: 0228-3821-1402, E-Mail: gerold.heinrichs@dlr.de

Apollonia Pane, Scientific Officer, Deutsches Zentrum für Luft- und Raumfahrt e. V. (DLR), Heinrich-Konen-Straße 1, 53227 Bonn, Tel.: 0228-3821-1995, E-Mail: apollonia.pane@dlr.de

\footnotetext{
${ }^{1}$ The advantages and disadvantages of open access and the underlying debate are not subject to this investigation and are therefore not discussed in further detail.
} 
${ }^{2}$ The advantages of open access mentioned here are based on the Horizon2020 Open Access Guidelines (European Commission, 2013).

${ }^{3}$ Open access is one of several components of open science: "Open science is more than open access to publications or data; it includes many aspects and stages of research processes. [...] [O]pen science is a broader concept that also includes the inter-operability of scientific infrastructure, open and shared research methodologies [...], and machine-friendly tools allowing, for example, text and data mining." (OECD Working Party on Innovation and Technology Policy, 2014). The documents that accompany the Framework Programmes for Research usually refer to open access and not to open science.

${ }^{4}$ Cf. for example the European Commission's website on the "Digital Agenda for Europe" or on the "European Research Area".

${ }^{5}$ Communication "Towards better access to scientific information: Boosting the benefits of public investments in research" (European Commission, 2012) and the Recommendation to the EU member states titled "Commission Recommendation on access to and preservation of scientific information" (European Commission, 2012b).

According to the Commission's recommendations, political measures to guarantee open access to the results of scientific investigation should at least be implemented in instances where the research was funded by public money (European Commission, 2012b, section L 194/39).

${ }^{6}$ Grey literature defined as "a collective term for any publication not connected with publishing companies. Grey literature is frequently published by institutions and organisations such as government bodies, authorities, research institutions, universities, museums, companies, associations, parties etc." (Glossar

Informationskompetenz, translation by the authors).

${ }^{7}$ European Commission, 2013.

${ }^{8}$ Green open access refers to freely accessible parallel publication or self-archiving on websites or document servers (known as 'repositories'); while gold open access implies that the article is made available directly in an open access journal. While these journals usually implement a peer review process, this is not the case with many repositories. (Peter Suber "Open Access Overview").

${ }^{9}$ Please also refer to Article 29 of the "H2020 Annotated Model Grant Agreement" (European Commission, 2015) for information concerning the regulations on publishing project results.

${ }^{10}$ European Commission, 2013.

${ }^{11}$ European Commission, 2012c, Annex II.30.

${ }^{12}$ European Commission, publication date unknown.

${ }^{13}$ Cf. OpenAIRE entry on Cordis. The original FP7 OpenAIRE gave rise firstly to OpenAIREplus (under FP7) and later (under Horizon) to the current Open AIRE2020 project (“General Information" on OpenAIRE website).

${ }^{14} \mathrm{Cf}$. OpenAIRE page on "FP7 post-grant Open Access publishing funds pilot".

${ }^{15}$ Cf. FP7 INCO entry on Cordis.

${ }^{16} \mathrm{~A}$ detailed list of the projects investigated is provided in the annex (separately uploaded online, address at the end of the article).

${ }^{17} \mathrm{Cf}$. additional examples of FP7 INCO project results in the annex separately uploaded online.

${ }^{18}$ In order to verify this, the projects' most important goals were examined with the assistance of the project summaries retrievable via the Cordis database (see below). We wanted to find out about possible dissemination methods for the project results (e.g. in writing on websites, orally at events, etc.).

${ }^{19}$ For the problems linked to open access from the perspectives of the result producers and searchers also see Fig. 4.

${ }^{20}$ Cf. Cordis website "About CORDIS".

${ }^{21}$ Cf. NEW INDIGO entry on Cordis.

${ }^{22}$ Following completion of research, the authors of this article have taken the necessary measures to create open access to the results of INCO projects in which they participated or which they coordinated.

${ }^{23}$ Zenodo is maintained and developed by CERN (European Organisation for Nuclear Research); however, they state that long-term funding of Zenodo is uncertain (see "FAQ" on the Zenodo website).

24 "ZENODO builds and operate a simple and innovative service that enables researchers, scientists, EU projects and institutions to share and showcase multidisciplinary research results (data and publications) that are not part of the existing institutional or subject-based repositories of the research communities." (European Commission Library and e-Resources Centre).

${ }^{25}$ Along with reports, workshop presentations and similar media could in theory also be stored in Zenodo. This means that the essential requirements for a comprehensive open science approach are already met.

${ }^{26} \mathrm{Cf}$. process description in the annex separately uploaded online. 